\title{
¿EXISTE UNA AUTÉNTICA DEMOCRACIA SINDICAL EN ESPAÑA?
}

M. ${ }^{a}$ DOLORES MARTÍNEZ CUEVAS 



\title{
¿EXISTE UNA AUTÉNTICA DEMOCRACIA SINDICAL EN ESPANA?
}

\author{
POR \\ M. ${ }^{a}$ DOLORES MARTÍNEZ CUEVAS \\ Profesora Contratada Doctora. Departamento de Derecho Constitucional \\ Universidad de Granada
}

\section{APROXIMACIÓN A ALGUNOS CONCEPTOS BÁSICOS DESDE LA PERSPECTIVA DEL DERECHO CONSTITUCIONAL}

El origen de la posición de marginación de la mujer en el mercado laboral no es el «sexo», sino el "género», pues el vocablo «sexo» no comparte ni matices ni contenido con el vocablo "género». El primero, «sexo, se halla muy vinculado y de modo prácticamente exclusivo con "identidad sexual», y tiene implicaciones simplemente biológicas, no obstante, la «identidad de género» tiene muchas más implicaciones de índole cultural. El género alude a la manera de acomodarse la persona a una organización social que atribuye «valores, expectativas, roles y funciones sociales» diversos dependiendo del «sexo biológico». Es decir, la "discriminación" femenina no se origina en la naturaleza sino en el "género" y posee una connotación «cultural», que sí se puede alterar ${ }^{1}$.

${ }^{1}$ PÉREZ DEL RÍO, T.: «Aproximación general a la Ley Orgánica de Igualdad Efectiva entre mujeres y hombres», en: Artículo 14. Una perspectiva de género. Boletín de Información y Análisis Jurídico, núm. 24, mayo de 2007, pág. 3. 
La «identidad de género» equivale a que los papeles atribuidos dependiendo del «sexo» sean distintos, pero además equivale a que el valor asignado al papel que la sociedad ha repartido a las féminas como grupo, ha sido y es hoy día más bajo del papel que socialmente se atribuye a los varones. Ello ha ocasionado una situación de discriminación social y económica de las mujeres como grupo, que se pone de relieve en las estadísticas realizadas por instituciones y organismos internacionales, europeos y españoles. La situación de discriminación de la mujer a que conduce otorgar funciones sociales poco apreciadas, choca con el derecho a igual dignidad, trato y oportunidades que nuestra Constitución consagra en los artículos $1,9.2$ y $14^{2}$.

En los últimos años, existe un gran interés y concienciación por el problema de la escasa intervención de las mujeres en la adopción de decisiones políticas y en la asunción de responsabilidades al más alto nivel dentro de los órganos políticos representativos. Esta problemática se ha hecho patente no sólo entre los grupos feministas, sino también en el plano del derecho internacional, del derecho comunitario y del derecho comparado y se ha plasmado en la adopción de un conjunto de iniciativas y medidas cuya principal finalidad consiste en tratar de implantar la democracia paritaria o paridad politica ${ }^{3}$.

La concepción sobre la democracia paritaria descansa en una realidad: el sexo femenino constituye la mitad de la población, por tanto, se estima de justicia que obtenga un porcentaje proporcional de "poder». Teniendo en cuenta que en el panorama presente el margen de actuación político de la mujer es muy bajo, se persigue que cada sexo no disponga de «un peso menor del 40 por ciento, ni superior al 60 por ciento» en el órgano representativo de que se trate ${ }^{4}$. En otros términos, la paridad política trataría de buscar que las mujeres superen el «techo de cristal» y participen de forma progresiva y comparable a la de los varones en el campo de lo público, reduciendo significativamente el espacio que dista entre el sexo masculino y femenino en este tema ${ }^{5}$.

En cualquier caso, para introducirnos mínimamente en la complejidad que plantea la democracia paritaria, es conveniente distinguir, siquiera sea someramente, algunos conceptos previos como: igualdad (formal y sustancial), dife-

${ }^{2}$ Ibídem.

3 TRUJILLO, Ma.A.: "La paridad política», en: ALVAREZ CONDE, E. et alii: Mujer y Constitución en España. Madrid: Centro de Estudios Políticos y Constitucionales, 2000, págs. 355356. Esta autora utiliza indistintamente ambas expresiones.

${ }^{4}$ BIGLINO CAMPOS, P.: «Las mujeres en los partidos políticos: representación, igualdad y cuotas internas», en: ALVAREZ CONDE, E. et alii: Mujer y Constitución en España, op. cit., págs. 412-413.

5 TRUJILLO, Ma A.: «La paridad política», op.cit., pág. 355. 
renciación, discriminación directa e indirecta, acción positiva (o medidas de acción positiva), discriminación inversa y cuotas.

Como es sabido, la igualdad se enmarca en la Constitución española de 1978 dentro de un Estado social y democrático de Derecho. Por tanto, el principio de igualdad implica tres perspectivas: la liberal, la democrática y la social. Desde la perspectiva liberal, el principio de igualdad propugna la igualdad formal de todos en la aplicación de la ley. La perspectiva democrática conlleva el derecho de toda la ciudadanía a ser protagonista y tomar parte activa en el sistema democrático, bien desempeñando las funciones y cargos públicos, bien decidiendo quién va a ejercer legítimamente el poder. La perspectiva social ha supuesto que la igualdad se transforme en una igualdad material eliminando las desigualdades fácticas presentes en nuestra sociedad (económicas, sociales, etc.). Para ello hay que interpretar conjuntamente los artículos 14 y 9.2 de la CE. A los efectos de este trabajo, el primero de ellos (el artículo 14) reconoce el derecho de igualdad de todos los españoles ante la ley, sin que pueda existir un trato discriminatorio por razón de sexo. Mientras que el segundo precepto ordena a los poderes públicos remover los obstáculos que impidan que se logre una igualdad auténtica y efectiva.

Pero habría que delimitar claramente entre diferenciación y discriminación. Ambos se consideran tratos desiguales pero el primero está permitido por la Constitución, mientras que el segundo está totalmente prohibido por esta última. Solamente se admite un trato desigual, o lo que es lo mismo, una diferenciación si existe una motivación "suficiente, fundada y razonable»" Si el diferente trato jurídico es realizado basándose en alguno de los motivos prohibidos por el art. 14 de nuestra Constitución (como los sexuales) la igualdad se convierte en el derecho fundamental a no sufrir discriminación sexual. Este derecho fundamental tiene como principal finalidad la paridad de los sexos ${ }^{7}$.

Por discriminación directa por razón de sexo entiende el artículo 6 de la Ley Orgánica 3/2007, de Igualdad Efectiva de Mujeres y Hombres «la situación en que se encuentra una persona que sea, haya sido o pudiera ser tratada, en atención a su sexo, de manera menos favorable que otra en situación comparable.» Mientras que la discriminación indirecta por razón de sexo se produce cuando «una disposición, criterio o práctica aparentemente neutros pone a personas de un sexo en desventaja particular con respecto a personas del otro, salvo que dicha disposición, criterio o práctica puedan justificarse objetivamente en atención a

6 TRUJILLO, Ma A.: «La paridad política», op.cit., pág. 357-358.

7 REY MARTÍNEZ, F.: El derecho fundamental a no ser discriminado por razón de sexo, op. cit., pág. 109. 
una finalidad legítima y que los medios para alcanzar dicha finalidad sean necesarios y adecuados.»

Otro de los términos que más frecuentemente se han venido manejando en temas de discriminación por razón de género ha sido el de acción positiva. En este sentido, la L.O. 3/2007, en su artículo 11 contempla que para lograr la efectividad del principio de igualdad, «los Poderes Públicos adoptarán medidas específicas en favor de las mujeres para corregir situaciones patentes de desigualdad de hecho respecto de los hombres. Tales medidas, que serán aplicables en tanto subsistan dichas situaciones, habrán de ser razonables y proporcionadas en relación con el objetivo perseguido en cada caso.»

Se trata de medidas temporales, hasta que permanezcan dichas situaciones, y que tienen una limitación más: la razonabilidad y la proporcionalidad. Medidas que consisten en poner fin a una situación tradicionalmente discriminatoria hacia las mujeres. La finalidad de estas medidas es acabar con estereotipos clásicos mientras éstos subsistan. Estas medidas de acción positiva que han de llevar a cabo los poderes públicos han sido unas medidas fuertemente contestadas y debatidas por el hecho de que traten de forma más positiva y favorable a un colectivo, el femenino, en perjuicio del masculino para tratar de equilibrar la balanza que tradicionalmente se ha inclinado a favor del género masculino.

En otras palabras, la acción positiva es uno de los tratos desiguales que permiten lograr la igualdad material, porque dicha acción beneficia a concretos sectores de la sociedad con unos rasgos concretos, visibles y constantes, que lo colocan en una situación desfavorable en relación a gran parte de la sociedad. La «discriminación inversa como acción positiva» implica que, en un contexto concreto, se produce una discriminación a favor de un grupo, optando por los componentes de un colectivo (féminas) en perjuicio de otro, o bien reservando a los integrantes de ese específico colectivo un cupo concreto, causando un perjuicio directamente sobre terceras personas ${ }^{8}$.

Respecto a las cuotas como medidas de discriminación inversa (reserva de plazas al sexo femenino en los órganos de dirección y en las listas electorales de un partido, o la cuota sindical) para que las mujeres estén más representadas y, especialmente, sobre las cuotas electorales ha existido un rico y polémico debate en torno a su compatibilidad constitucional. Hay autores que defienden enérgicamente las cuotas mientras que otros las atacan apasionadamente.

La Ley de Cuotas es un mecanismo que discurre dentro del concepto de discriminación positiva y mediante ella se persigue la finalidad de generar una pla-

8 TRUJILLO, Ma A.: «La paridad política», op.cit., pág. 358-360. 
taforma equivalente entre mujeres y hombres en la incorporación a los puestos de poder en diferentes campos. En cualquier caso, en una Ley de Cuotas se determinan cuotas mínimas y máximas a la hora de formar parte, en función del sexo, en candidaturas y porcentajes de puestos elegidos en elecciones parlamentarias y locales. En Sudamérica doce Estados cuentan con una Ley de Cuotas en su normativa que oscila entre el 25 y el $40 \%$. La primera Ley de Cuotas se aprobó en Argentina en 1991. Los partidos socialistas en los distintos Estados sudamericanos han sido los pioneros para el establecimiento de las cuotas en la participación de las mujeres?.

El tipo de cuotas varía desde las que se incorporan en las Constituciones, hasta las que se introducen en la legislación (en Sudamérica las cuotas se fijan en la legislación electoral) o las que se determinan por los mismos partidos políticos. Además, pueden ser facultativas u obligatorias.

Aparte de la cuota (que provoca que sean visibles las mujeres en las listas) es imprescindible que estas mujeres se coloquen en puestos con probabilidades auténticas de ser electas, pues a menudo ocurren supuestos donde se las sitúa al final de las listas electorales para incrementar la proporción. El medio más eficiente para afrontar estos casos consiste en la incorporación del sistema cremallera, donde se alternan hombres y mujeres en las listas ${ }^{10}$.

Entre los defensores de las cuotas se justifica la legitimidad de éstas en beneficio del sexo femenino porque sirven para eliminar la «discriminación positiva» de la que secularmente se han aprovechado los hombres. En este sentido, gráficamente se manifiesta que los varones "han formado una verdadera 'casta', que ha mantenido 'cuotas' casi del cien por cien sólo para ellos.» ${ }^{11}$ Asimismo, se defiende la legitimidad constitucional de imponer cuotas, aunque hay que ir con cautela no imponiéndolas sin más, ya que sólo se han de aplicar como remedio subsidiario a casos específicos de discriminación como la sexual, y son medidas de naturaleza temporal ${ }^{12}$.

Haciendo abstracción de la inevitable politización de estas cuotas reservadas al sexo femenino, éstas encontrarían su apoyo en dos motivos, en opinión de A. Ruiz Miguel: a) si nos atenemos a su finalidad persiguen «una sociedad más

9 BOIX, M.: «La representación de las mujeres y la lucha por la paridad, aproximación histórica», en: El periódico feminista en red, 1 de julio de 2005, http://www.mujeresenred.net/

${ }^{10}$ Ibídem, pág. 3.

${ }^{11}$ MARTÍNEZ SEMPERE, Eva: «La legitimidad de la democracia paritaria». Revista de Estudios Políticos, no 107, Nueva Época. Enero/Marzo 2000, pág.141.

12 REY MARTÍNEZ, F.: El derecho fundamental a no ser discriminado por razón de sexo, op. cit. 
igualitaria», y b) desde el punto de vista instrumental, buscan lograr que sea más fácil alcanzar trabajos socialmente relevantes como medio de superar los tradicionales obstáculos y muros infranqueables, que han impedido a las mujeres participar activamente en la mayor parte de las altas esferas del poder. Propone meditar sobre si tales cuotas se acomodaban en nuestro país a la Constitución y, especialmente, planteaba modificar la Ley Orgánica de Régimen Electoral General (L.O.R.E.G.) para que fijase el deber de cualquier lista de candidatos de reservar un determinado número para mujeres aspirantes a ser elegidas democráticamente ${ }^{13}$.

Esto último se ha conseguido con la aprobación de la L.O. 3/2007, para la Igualdad Efectiva de Mujeres y Hombres, que ha incorporado en la LOREG el art. 44 bis con la siguiente redacción:

Las candidaturas presentadas a las elecciones de diputados al Congreso, municipales, europeas, autonómicas «deberán tener una composición equilibrada de mujeres y hombres, de forma que en el conjunto de la lista de los candidatos de cada uno de los sexos supongan como mínimo el cuarenta por ciento. Cuando el número de puestos a cubrir sea inferior a cinco, la proporción de mujeres y hombres será lo más cercana posible al equilibrio numérico.»

Los detractores de las cuotas, como L. Favoreu, opinan que las cuotas chocan con la «indivisibilidad del cuerpo electoral» ${ }^{14}$. Afirmación que es rebatida por algunas autoras que opinan que ni las cuotas, como una de las vías posibles que conducen a la democracia paritaria, ni ésta última implican una quiebra en el electorado ${ }^{15}$.

En definitiva, con estas nociones (democracia paritaria o paridad política) no estamos aludiendo sólo a la conveniencia de implantar cuotas, sino más bien se pretende articular temporalmente unas actuaciones, hasta lograr unos fines más justos y una sociedad que se acerque mucho más a la igualdad real desde la perspectiva política, donde el sexo no condicione en modo alguno la distribución de los roles. Por tanto, la democracia paritaria no ha de ser sólo cuantitativa, acercando los porcentajes de representación de uno y otro sexo, sino ante todo se trata de concebir la democracia paritaria en términos cualitativos, como un com-

13 RUIZ MIGUEL, A.: "Paridad electoral y cuotas femeninas.» Claves de Razón Práctica, núm. 94, julio/agosto 1999, pág. 48.

14 FAVOREU, L.: «Principio de igualdad y representación política de las mujeres.» Revista Española de Derecho Constitucional, no 50, año 17. Mayo/Agosto 1997, pág. 24.

15 BIGLINO CAMPOS, P.: «Las mujeres en los partidos políticos: representación, igualdad y cuotas internas», en: ALVAREZ CONDE, E. et alii: Mujer y Constitución en España, op. cit., pág. 413. 
ponente esencial de la democracia contemporánea y, en definitiva, de los derechos más básicos del sexo femenino ${ }^{16}$.

Gráficamente, no se trata de dar unos pequeños toques de maquillaje a la democracia (mediante las cuotas o los porcentajes en favor de las mujeres) para disimular sus carencias y que parezca igualitaria. A mayor escala se trataría de realizar una auténtica operación de cirugía política con la finalidad de que se transforme en una auténtica democracia paritaria, donde el protagonismo político activo, sindical, económico, etc. de la mujer sea real y equilibrado con el protagonismo masculino ${ }^{17}$.

Haciendo un paralelismo podemos pensar en la necesidad de la democracia sindical o de la paridad sindical. Máxime si nos basamos en el artículo 7 de la Constitución Española que tras manifestar que los sindicatos «contribuyen a la defensa y promoción de los intereses económicos y sociales que les son propios" y que "su creación y el ejercicio de su actividad son libres dentro del respeto a la Constitución y a la ley", finaliza con un mandato muy interesante a efectos de este trabajo, el de que "su estructura interna y funcionamiento deberán ser democráticos.»

Si hiciésemos una búsqueda a través de toda la L.O. 3/2007 quizás la frase más repetida sería la composición equilibrada. En este sentido, la Disposición adicional primera, entiende por presencia o composición equilibrada «la presencia de mujeres y hombres de forma que, en el conjunto a que se refiera, las personas de cada sexo no superen el sesenta por ciento ni sean menos del cuarenta por ciento".

$\mathrm{Al}$ respecto, una de las finalidades establecidas en la Cumbre mundial de la mujer de Beijing (nombre chino de Pekín, la capital de China) celebrada en 1995, consistió en que diez años más tarde existiese la democracia paritaria. Es decir, el propósito era que en 2005 se lograra la incorporación auténtica de la mujer en los procesos de adopción de decisiones políticas en un $50 \%$.

\section{LA PARIDAD DEMOCRÁTICA NO ES SÓLO CUANTITATIVA}

Efectivamente, la problemática de la paridad no es sólo numérica. A medida que han ido incrementándose los porcentajes de participación femenina ha ido

16 TRUJILlO, Ma. A.: «La paridad política». En: ALVAREZ CONDE, E. et alii, op.cit., pág. 335.

${ }^{17}$ MARTÍNEZ CUEVAS, Ma . D.: «Igualdad y discriminación en materia de género, con especial incidencia en el ámbito de las organizaciones sociales y políticas. Equality and Sexual Discrimination in Social and Political.» En: Revista Electrónica de la Facultad de Derecho de la Universidad de Granada. www.refdugr.com Fecha de publicación: 1 de marzo de 2008. 
decreciendo el período que las mujeres continúan en sus puestos, éstas no logran afianzar su poder.

En este ámbito, como afirma la doctora en Filosofía Alicia Miyares: «La paridad implica consolidación del poder. Sin consolidación, se queda en una cuestión simplemente representativa. Si al final la paridad va a consistir en que seguimos perpetuando los estereotipos, la hemos vaciado de contenido.» ${ }^{18}$ En este sentido, la citada autora llevó a cabo una investigación sobre «Paridad y consolidación del poder de las mujeres», donde se prueba que el $60 \%$ de las diputadas en la Cámara Baja únicamente logra estar durante una legislatura.

Pero el problema radica además en que, según Alicia Miyares, estos datos y cifras obtenidos en el Congreso de los Diputados son «extrapolables a cualquier institución que sea representativa.» En la Cámara Baja las mujeres no logran afianzarse en el poder porque en el seno de los partidos políticos a que pertenecen «tampoco alcanzan la cifra del $25 \%$ en la permanencia», lo que pone de relieve que no logran conformar «un grupo de poder que pueda presionar.»

Coincide con esta afirmación Carmen del Campo, del Grupo Parlamentario Socialista, una parlamentaria que ha logrado estar nada más y nada menos que seis legislaturas en el Congreso, al considerar que «ocupar un sitio en el Congreso tiene que ver con el poder orgánico dentro de los partidos. Las mujeres, desde luego, tenemos menos poder, por eso entramos y salimos con tanta facilidad.»

Una de las explicaciones de este rápido paso de las mujeres por el poder nos la ofrece Ana Balletbó, otra de las diputadas socialistas que también ha estado seis legislaturas en la Cámara Baja: «En política, la permanencia tiene que ver primero con las lealtades políticas. Si el grupo en el que estás más o menos adscrito políticamente manda en el partido, las cosas van de una manera, y si no manda, van de otra. Luego está el elemento de la popularidad, la presencia mediática que tengas y la capacidad de liderazgo». Y denuncia una especie de engaño que conlleva la paridad política donde, aunque haya más mujeres que se incorporan a la política, sin embargo su paso por ésta es más fugaz.

Para afrontar este engaño Ana Balletbó plantea un remedio: «Hacer la renovación por la vía de las mujeres. Ese es el truco. Los responsables de los partidos políticos buscan mujeres muy profesionales a las que alquilan durante una legislatura y luego les dicen adiós. La mayoría de los independientes son

18 Alicia Miyares es doctora en Filosofía, Profesora de Filosofía de Enseñanza Secundaria y Profesora Colaboradora de la Universidad de Oviedo. Es miembro del Proyecto «El camino hacia la paridad». Estas declaraciones, así como las siguientes de Carmen del Campo y Ana Balletbó, fueron publicadas en la revista Interviú, núm. 1467, 7 de junio de 2004. 
mujeres. Cuando las cambian no tienen [a nadie] en el partido porque ellas no cuentan con quien las defienda.»

La preocupación y el combate de gran parte del feminismo se ha decantado a lo largo de mucho tiempo por «el derecho a estar presente, porque las mujeres tengan el mismo derecho a equivocarse que los hombres, también el mismo derecho a la incompetencia y a la competencia que ellos.» ${ }^{19}$

Sea como sea, es cierto que en nuestro país, el gobierno formado por el socialista José Luís Rodríguez Zapatero es el primero con una composición paritaria: el 50\% de hombres y el 50\% de mujeres entre los años 2004 a 2006 (en 2007 ha bajado a un 43,75\%). Después del último cambio efectuado en el Gobierno socialista de Zapatero en el año 2008 hay más Ministras que Ministros. No obstante, no podemos quedar deslumbrados por el brillo de estos porcentajes, pues en el nivel inferior de gobierno, Secretarias de Estado, Directoras Generales, el porcentaje de incorporación de mujeres no ha supuesto una composición equilibrada entre el 40 y el 60 por ciento requerido por nuestra Ley de Igualdad. Efectivamente, según las estadísticas ofrecidas por el Instituto de la Mujer con el último cambio experimentado en el gabinete del socialista J.L. Rodríguez Zapatero en 2008: en el nivel de los altos puestos de la Administración pública del Estado, las féminas consiguen sólo 32 cargos de cada 100. A diferencia del cargo de Subsecretaria/o donde la incorporación femenina es de un (27,5\%), el número de Secretarias de Estado equivale a una tercera parte del total ${ }^{20}$.

Y para qué hablar de otras instancias supremas del poder, que aún siguen siendo selectivas y elitistas: prácticamente sólo están ocupadas por varones. Por poner algunos ejemplos, en el Poder Judicial, la Presidencia del Tribunal Supremo, entre 1995 y 2005 no ha estado ocupada por ninguna mujer, pese a que las juezas de a pie son mayoría $(64,13 \%)$. En este Tribunal, los datos nos indican que en 2007 las mujeres magistradas ocupan en torno al 8\% de los cargos, porcentaje algo mayor que en 2006. No obstante, este aumento se debe a la bajada en el porcentaje de magistrados masculinos en el Tribunal Supremo y no a la subida del porcentaje de magistradas femeninas que no ha sufrido variación alguna.

Durante el año 2007 se ha incrementado un $0,8 \%$ el tanto por ciento de féminas en el Poder Judicial, y se confirma la tendencia de años pasados donde la base de la pirámide judicial descansa en un elevado porcentaje de mujeres juezas

19 BOIX, M.: «La representación de las mujeres y la lucha por la paridad, aproximación histórica», en: El periódico feminista en red, 1 de julio de 2005, http://www.mujeresenred.net/

${ }^{20} \mathrm{http} / /$ www.migualdad.es/mujer/publicaciones/docs/Mujeres\%20y\%20hombres 09.pdf. En este sentido, podemos ver también VARELA, N.: Feminismo para principiantes, Ediciones B, S.A., 2005, Barcelona, $1^{\text {a }}$ ed. 2005. http://www.modemmujer.org/docs/11.262.htm 
y este porcentaje de participación va rebajándose conforme se sube en la pirámide judicial. A mayor responsabilidad en el Poder Judicial, menor implicación femenina. Los altos puestos donde se toman las decisiones más relevantes para el Poder Judicial se dejan hasta ahora en manos de los hombres, con gran diferencia numérica respecto de las mujeres ${ }^{21}$.

La participación de la mujer en los altos cargos del Consejo de Estado ha sido nula hasta que en 2007 la presencia de la mujer es de un 6,67\%. El porcentaje de mujeres Presidentas de Gobiernos autonómicos ha rondado el 5\% durante los años 2004 a 2006. Tampoco hemos tenido hasta el momento ninguna mujer Gobernadora o Subgobernadora del Banco de España ${ }^{22}$.

A tenor de los datos suministrados por la Encuesta de Población Activa (EPA), hay cifras esperanzadoras en el sector económico. Sin ánimo de ser exhaustivos en este sector, en números absolutos el número de mujeres que dirigen o son gerentes de una empresa ha ascendido un 1.4\%, es decir, en 2007 había 505.800 mujeres directivas en 2007, y en 2008 ya son 513.100. Por el contrario, la bajada más notable en esta etapa ha tenido lugar a la hora de dirigir organizaciones con 10 o más trabajadores "del poder ejecutivo y legislativo.» En cifras absolutas, la cantidad de directivas se ha transformado de 1.320 en 2007 a 1.040 en 2008, ocasionándose una bajada del $21,2 \%{ }^{23}$.

Como corolario a todos estos porcentajes, datos y cifras, basta detener nuestra atención y observar que las decisiones políticas que adoptan las mujeres tienen relación normalmente con las áreas de la mujer, las políticas igualitarias y los «servicios sociales», perpetuando así el tradicional papel asignado tradicionalmente a la mujer como propiciadora de cuidados de los mayores y prolongando el rol históricamente encomendado al sexo femenino de "cuidadoras». ¿No va siendo hora ya de reivindicar, por cierto, que las políticas de las mujeres se descuelguen de los ministerios y departamentos de temáticas «sociales» para tener entidad propia? ${ }^{24}$

Qué duda cabe que el final del siglo XX y los comienzos del XXI han sido importantes y positivos para las mujeres. Desde la perspectiva planetaria se ha logrado la visibilización de los problemas más acuciantes y aunque las sociedades

${ }^{21}$ http://www.migualdad.es/mujer/publicaciones/docs/Mujeres\%20y\%20hombres 09.pdf

22 Datos estadísticos obtenidos en la antigua página web del Instituto de la Mujer: http://www.mta.es/mujer/mujeres/cifras/poder/index.htm. Los últimos datos que he obtenido en agosto de 2009 nos lo ofrece el Instituto de la Mujer en una nueva dirección web: http://www.migualdad.es/mujer/publicaciones/docs/Mujeres\%20y\%20hombres 09.pdf

${ }^{23} \mathrm{http} / /$ www.migualdad.es/mujer/publicaciones/docs/Mujeres $\% 20 \mathrm{y} \% 20$ hombres $09 . \mathrm{pdf}$

24 BOIX, M.: «La representación de las mujeres y la lucha por la paridad, aproximación histórica», en: El periódico feminista en red, 1 de julio de 2005, http://www.mujeresenred.net/ 
se resistan, a nadie se le escapa que la presencia de las mujeres en el espacio público es imposible de frenar. Dicho esto, debemos reconocer también que incluso en las condiciones más propicias para las mujeres, son los hombres quienes continúan decidiendo cuáles son las mujeres que están y en qué puestos de responsabilidad. Nos dan cargos para trabajar pero siguen controlando de manera absoluta el poder de decisión ${ }^{25}$.

\section{PANORAMA JURÍDICO ACTUAL}

Como ya hemos visto, el artículo 14 de la Constitución española proclama el derecho a la igualdad y a la no discriminación por razón de sexo. Por su parte, el artículo 9.2 consagra la obligación de los poderes públicos de promover las condiciones para que la igualdad del individuo y de los grupos en que se integra sean reales y efectivas.

La igualdad entre mujeres y hombres es un principio jurídico universal reconocido en diversos textos internacionales sobre derechos humanos, entre los que destaca la Convención sobre la eliminación de todas las formas de discriminación contra la mujer, aprobada por la Asamblea General de Naciones Unidas en diciembre de 1979 y ratificada por España en 1983. En este mismo ámbito procede evocar los avances introducidos por conferencias mundiales monográficas, como la de Nairobi (Kenia) de 1985 y Beijing (China) en 1995.

La igualdad es también un principio fundamental en la Unión Europea. A partir de la entrada en vigor del Tratado de Ámsterdam, el 1 de mayo de 1999, la igualdad entre mujeres y hombres y la eliminación de las desigualdades entre unas y otros son un objetivo que debe integrarse en todas las políticas y acciones de la Unión y de sus miembros.

Basándose en el antiguo artículo 111 del Tratado de Roma, se ha desarrollado un acervo comunitario sobre igualdad de sexos de gran importancia, a cuya adecuada transposición (aplicación) se dirige, en buena medida, la Ley Orgánica 3/2007. En particular, esta Ley incorpora al ordenamiento español dos directivas en materia de igualdad de trato, la Directiva 2002/73/CE, de reforma de la Directiva 76/207/CEE, relativa a la aplicación del principio de igualdad de trato entre hombres y mujeres en lo que se refiere al acceso al empleo, a la formación y a la promoción profesionales, y a las condiciones de trabajo; y la Directiva 2004/113/CE, sobre aplicación del principio de igualdad de trato entre hombres $y$ mujeres en el acceso a bienes y servicios y su suministro.

25 Ibídem. 


\section{SITUACIÓN CONCRETA EN ESPAÑA: LA NUEVA LEY ORGÁNICA PARA LA IGUALDAD EFECTIVA DE MUJERES Y HOMBRES \\ DE MARZO DE 2007}

La Ley Orgánica 3/2007 en su Exposición de Motivos insiste en la idea de que el pleno reconocimiento de la igualdad formal ante la ley, aunque ha supuesto una conquista importante, ha resultado ser insuficiente. Es necesaria una acción normativa dirigida a combatir todas las manifestaciones aún existentes de discriminación, directa o indirecta, por razón de género. Esta exigencia se deduce de nuestro ordenamiento constitucional y supone un auténtico derecho de las mujeres, aunque también se presenta como un elemento enriquecedor de la propia sociedad española.

Esta solución conlleva la necesidad de un compromiso de los poderes públicos para hacer efectiva y palpable esta ley, a través de políticas públicas en todos los ámbitos del territorio y que atraviesen todos los sectores: sociales, deportivos, culturales, académicos, universitarios, sindicales, económicos, laborales, etc. La Ley se refiere a la generalidad de las políticas públicas en España, tanto estatales como autonómicas y locales. Por eso, se afirma la dimensión transversal del principio de igualdad. La Ley nace con la vocación de erigirse en la leycódigo de la igualdad entre mujeres y hombres.

Para ello se disponen una serie de instrumentos en el campo de la Administración General del Estado:

- un Plan Estratégico de Igualdad de Oportunidades,

- la constitución de una Comisión Interministerial de Igualdad con responsabilidades de coordinación,

- los informes de impacto de género,

- y los informes o evaluaciones periódicos sobre el cumplimiento efectivo del principio de igualdad.

Pero el compromiso de promocionar el principio de igualdad ha de partir también de las relaciones entre particulares y de las empresas privadas. De ahí que se ha considerado oportuno fijar concretas actuaciones de promoción de la igualdad efectiva en las empresas privadas, como las que se regulan en el tema de contratación o de subvenciones públicas o en referencia a los consejos de administración.

Singular interés tiene la ley por la corrección de la desigualdad en el ámbito específico de las relaciones laborales. Gracias a un conjunto de previsiones, se contempla el derecho a compatibilizar la existencia privada (personal y familiar) 
con la existencia laboral y se propicia una mayor corresponsabilidad entre mujeres y hombres a la hora de hacerse cargo de las obligaciones familiares.

La Ley promueve que se tomen actuaciones singulares y determinadas que favorezcan la igualdad en las empresas, ubicándolas en el marco de la negociación colectiva, para que sean las partes, libre y responsablemente, las que acuerden su contenido.

De la preocupación por el alcance de la igualdad efectiva en nuestra sociedad no podía quedar fuera el ámbito de la participación política, tanto en su nivel estatal como en los niveles autonómico y local, así como en su proyección de política internacional de cooperación para el desarrollo. El denominado principio de presencia o composición equilibrada, con el que se trata de asegurar una representación suficientemente significativa de ambos sexos en órganos y cargos de responsabilidad, se lleva así también a la normativa reguladora del régimen electoral general. Y se opta por una fórmula con la flexibilidad adecuada para conciliar las exigencias derivadas de los artículos 9.2 y 14 de la Constitución con las propias del derecho de sufragio pasivo incluido en el artículo 23 del mismo texto constitucional. Se asumen así los recientes textos internacionales en la materia y se avanza en el camino de garantizar una presencia equilibrada de mujeres y hombres en el ámbito de la representación política, con el objetivo fundamental de mejorar la calidad de esa representación y con ella de nuestra propia democracia.

En el Título I de esta Ley Orgánica se menciona el principio de igualdad de trato entre mujeres y hombres que implica «la ausencia de toda discriminación, directa o indirecta, por razón de sexo, y, especialmente, las derivadas de la maternidad, la asunción de obligaciones familiares y el estado civil.»

El principio de igualdad de oportunidades e igualdad de trato debe de impregnar el mundo del trabajo, tanto en el momento de lograr el empleo, como a la hora de su mantenimiento, de los ascensos, reciclaje y en todos aquellos aspectos que rodean al mundo laboral. Asimismo, a la hora de militar y de formar parte de los sindicatos y organizaciones de empresarios.

Bajo la expresiva denominación «El derecho al trabajo en igualdad de oportunidades» contempla en el Título IV cuatro Capítulos, en los que nos vamos a detener seguidamente.

- El primero de ellos, titulado «Igualdad de trato y de oportunidades en el ámbito laboral» se ocupa de Programas para mejorar el empleo de las mujeres. Concretamente, estos Programas englobarán «todos los niveles educativos y edad de las mujeres, incluyendo los de Formación Profesional, Escuelas Taller y Casas de Oficios, dirigidos a personas en desempleo", y tendrán como destino prioritario grupos específicos de mujeres. Tam- 
bién gracias a la negociación colectiva se podrán fijar «medidas de acción positiva para favorecer el acceso de las mujeres al empleo».

- El segundo trata el modo de armonizar la vida privada, (individual y familiar) con la laboral, para propiciar «la asunción equilibrada de las responsabilidades familiares, evitando toda discriminación basada en su ejercicio», regulando los temas del permiso por maternidad así como el permiso por paternidad. Este último es calificado en la Exposición de Motivos de la propia Ley "la medida más innovadora» para propiciar la armonización de la existencia privada y laboral. Es un derecho «individual y exclusivo» del progenitor, y que dura quince días $(13+2)$, incrementándose si se trata de parto múltiple en dos días más por cada hijo a partir del segundo vástago.

Como novedad dispone el tercer Capítulo "planes de igualdad de las empresas», negociándolos o consultándolos previamente con la representación legal de los trabajadores y trabajadoras. Estos planes, obligatorios en las empresas que cuenten con más de 250 empleados/as, serán de implantación voluntaria en las pequeñas y medianas empresas. Independientemente de ello, estos planes podrán ir acompañados de medidas específicas encaminadas a prevenir toda clase de discriminación en el trabajo por razón de género y a promocionar la igualdad.

Llegándose, incluso, en el Capítulo Cuarto a regular el «distintivo empresarial en materia de igualdad». Para lograrlo se tendrán en cuenta, entre otros criterios, "la presencia equilibrada de mujeres y hombres en los órganos de dirección y en los distintos grupos y categorías profesionales de la empresa, la adopción de planes de igualdad u otras medidas innovadoras de fomento de la igualdad, así como la publicidad no sexista de los productos o servicios de la empresa.»

El Título V, en su Capítulo I, recoge los criterios de actuación de las Administraciones públicas en relación con el empleo público, entre los que destacamos los siguientes:

a) «Facilitar la conciliación de la vida personal, familiar y laboral, sin menoscabo de la promoción profesional»,

b) «Promover la presencia equilibrada de mujeres y hombres en los órganos de selección y valoración» o

c) «Establecer medidas efectivas para eliminar cualquier discriminación retributiva, directa o indirecta, por razón de sexo».

Podríamos aportar muchas cifras, datos, estadísticas que pongan de manifiesto los obstáculos reales que dificultan la participación de las mujeres en los 
órganos de decisión y de responsabilidad de un sindicato. Pero sólo daremos algunos ejemplos que ponen de relieve los obstáculos que impiden la implicación de las mujeres en las más altas instancias de decisión y de responsabilidad de los sindicatos.

Efectivamente, los datos demuestran que la afiliación a los dos sindicatos mayoritarios en España, Comisiones Obreras (CCOO) y Unión General de Trabajadores (UGT) se ha incrementado entre 1995 y 2006. En cuanto al porcentaje de mujeres, se ha pasado de un $24,71 \%$ a un $32,03 \%$ en UGT, mientras que el porcentaje ha sido mayor en Comisiones, que ha pasado de un 23 a un 36 por ciento de mujeres afiliadas.

En lo relativo a los cargos ocupados en los principales sindicatos de trabajadores, los datos prueban que entre 1989 y 2006 la composición de la Comisión Ejecutiva Federal estaba en 2006 en un 30,30 por ciento de mujeres en Comisiones, en un 46,15 por ciento en UGT y en un 25 por ciento en el Sindicato USO, Unión Sindical Obrera. Observamos con atención que en ningún momento la Secretaría General de ninguno de estos tres sindicatos ha estado ocupado por una mujer.

Si nos centramos en el sector de Sanidad en Comisiones Obreras el porcentaje de afiliación femenino es muy alto (70 por ciento), lo que no se corresponde con el porcentaje de hombres que están en la cúpula en este sector, que es de un 80 por ciento de hombres y sólo un 20 por ciento de mujeres.

Con estos datos se demuestra objetivamente que la paridad sindical ahora mismo no existe en nuestro país.

Afortunadamente, vemos que el futuro parece que está cambiando. Es digno de señalar en este sentido que el $40^{\circ}$ Congreso Confederal de la UGT, celebrado en Madrid entre el 1 y el 4 abril de 2009, aprueba por unanimidad en el Plenario la Carta Sindical por la Igualdad. En este Congreso, Almudena Fontecha, miembro de la Comisión Ejecutiva Confederal, durante la presentación en rueda de prensa, junto al presidente del $40^{\circ}$ Congreso Confederal, Josep María Álvarez, de la citada Carta Sindical por la Igualdad manifestó que «El cambio de modelo productivo no puede hacerse sin contar con las mujeres, que están en el mercado laboral con vocación de permanencia, no de forma coyuntural.» España «está desaprovechando el capital humano que supone la formación de muchas de sus mujeres y esa es la reticencia que hemos tenido por parte de la patronal $\aleph^{26}$.

Por otra parte, la sindicalista Almudena Fontecha señaló que «el sistema de cuotas ha permitido que el sindicato tenga un número importante de mujeres en

${ }^{26}$ http://www.ugt.es/40_Congreso_Confederal_UGT/actualidad/a03042009_40_Congreso_UGT.htm 
los órganos de dirección, de participación del sindicato. El compromiso en este Congreso es incrementar esos niveles de participación para tender a una composición equilibrada de las mujeres y los hombres en nuestra organización.» ${ }^{27}$

Esperemos que esta Carta Sindical por la Igualdad dentro del sindicato UGT, no se quede en meras intenciones y que no sea una simple tendencia propia del momento en que vivimos y que en los próximos años podamos realmente constatar la existencia de una auténtica democracia sindical en nuestro país.

\section{ALGUNAS ESTRATEGIAS PROPUESTAS EN EUROPA OCCIDENTAL PARA FOMENTAR LA ASUNCIÓN DE RESPONSABILIDADES DE LA MUJER EN LOS SINDICATOS}

1. Respecto al cuidado de los hijos, de los mayores y de las personas dependientes a cargo de la familia:

- Residencias para personas mayores.

- Guarderías: mayor número de ellas y más asequibles.

- Centros de día para personas dependientes.

- Concentración de la jornada laboral (horario europeo).

- Permiso de paternidad por más tiempo (en la LO 3/2007 es de 13 más 2 días que es lo que había, lo que hace un total de 15 días, pero esto aún es insuficiente).

- Mejor reparto de los tiempos que dedican hombre y mujer al cuidado de los hijos, de las personas mayores y del hogar.

2. En el lugar de trabajo:

- Cuando se fije una reunión de trabajo que sea a primera hora de la mañana y que no se prolongue nada más que hasta media tarde.

- Que los temas de las reuniones se hayan previamente discutido por los asistentes a las mismas, de forma que circulen borradores a los que se les hagan enmiendas, rectificaciones, sugerencias por parte de los participantes en la reunión, etc... a través de correo electrónico, por ejemplo.

${ }^{27}$ Ibídem 
- Que los temas no se discutan en reuniones informales (bar, cafetería ...) como nos tienen acostumbrados los hombres, sino en el lugar de trabajo para que puedan participar y decidir también las mujeres.

- Sensibilizar a todos los trabajadores y trabajadoras de la importancia de que las mujeres accedan y desempeñen sus cargos de responsabilidad y toma de decisiones en el sindicato, dado que son beneficiosos para toda la sociedad (ésta será más justa e igualitaria) y para nuestro sistema democrático. En este sentido, las campañas informativas pueden ser públicas y privadas.

- Periódicamente que se reciclen, que se formen todos y todas los trabajadores del sindicato en materias de género. Se trataría de cursos impartidos por personas expertas en estas materias. No se trata solamente de generar liderazgos femeninos para servirse del poder, sino que hay que pugnar por liderazgos femeninos con visión de justicia social.

- En definitiva, que se cumpla real y eficazmente el mandato constitucional que propone la estructura y funcionamiento democrático de un sindicato (art. $7 \mathrm{CE}$ ).

\section{Campañas publicitarias de carácter informativo}

- Periódicamente se pueden realizar campañas informativas, a través de todos los medios de comunicación, para tratar de que la afiliación sindical de las mujeres trabajadoras se incremente. En especial, en aquellos sectores donde la afiliación es baja, ya sea porque hay menos mujeres trabajando en dicho sector, ya sea por desinterés de las mujeres, o por dedicarles la mayor parte del tiempo a las labores domésticas y al cuidado y educación de los hijos.

- Asimismo, realizar campañas publicitarias en las que se haga hincapié en la importancia que tiene para las empresas, para el fortalecimiento y democratización de las organizaciones sindicales y para nuestro sistema democrático, la participación de las mujeres en las instancias de representación sindical. 


\section{ALGUNAS ESTRATEGIAS PROPUESTAS EN AMÉRICA DEL SUR PARA FOMENTAR LA ASUNCIÓN DE RESPONSABILIDADES DE LA MUJER EN LOS SINDICATOS}

Existen otras propuestas algo más amplias, que, pese a ser realizadas en Sudamérica, nos sirven perfectamente de cara a la realidad sindical en nuestro país. Es el caso de la I Conferencia Continental de Mujeres de las Américas (América del Sur), celebrada los día 27 a 29 de septiembre de 2004, en Ciudad de Panamá, República de Panamá ${ }^{28}$. A efectos de este trabajo destacamos algunas propuestas:

\section{En el ámbito sindical}

- Trabajar fuertemente para incrementar la afiliación y la participación activa de las mujeres en los sindicatos, promover la igualdad y paridad de género dentro de las estructuras, como condición para su fortalecimiento y su democracia interna.

- Ejecutar la política de acción positiva, de forma tal que se establezca en todos los estatutos de todas las organizaciones la cuota sindical de participación en los comités ejecutivos; así como la participación en todas y cada una de las comisiones sindicales, intersindicales y de representación en instancias bi y tri-partitas de negociación y diálogo.

Por ejemplo, en Argentina existe una ley de este tipo, la Ley del Cupo o Cuota Sindical, que es de 2002, y que establece un porcentaje mínimo de un 30 por ciento de mujeres dirigentes de sindicatos a todos los niveles ${ }^{29}$. Esta idea se reivindica en Sudamérica, en aquellos países donde no existe, en pro de la paridad sindical.

- Desarrollar programas sindicales para la igualdad de género y desarrollar en forma transversal la perspectiva de igualdad de género, en el accionar cotidiano de los sindicatos.

\footnotetext{
${ }^{28}$ http://www.oit.org.pe/WDMS/bib/virtual/coleccion_actrav/edob/2004/declara_1.pdf

${ }^{29}$ Esta ley establece que debe haber un mínimo de 30 por ciento de mujeres dirigentes sindicales y en las listas que elaboran los sindicatos de cara a las elecciones sindicales, aunque «lamentablemente eso no se cumple», según se puso de manifiesto por parte de Silvia Villaverde cuando fue entrevistada a raíz del Segundo Foro de Mujeres Sindicalistas, el 27 de octubre de 2009 en Buenos Aires (Argentina), en un artículo denominado "Cupo sindical para mujeres». http://www.rel-uita.org/mujer/con-silvia.htm. Amalia Antúnez Rel-UITA, Montevideo, 3 de noviembre de 2008 .
} 
- Pugnar por la autosuficiencia financiera y dar prioridad a la asignación presupuestaria necesaria para hacer sostenible los programas de igualdad de género.

- Asegurar la elección de mujeres prevista en los Estatutos vigentes, para fortalecer el liderazgo y la participación en los órganos de dirección.

- Difundir las prácticas exitosas de afiliación y participación de mujeres en los sindicatos.

- Fortalecer la perspectiva de género y las reivindicaciones respectivas en los procesos de negociación colectiva para garantizar: la igualdad en las condiciones de trabajo, en el acceso a la formación profesional, en la promoción y ascenso, el goce de los derechos a la protección de la maternidad y paternidad; $y$, en general, para eliminar cualquier práctica discriminatoria.

\section{En el ámbito sociopolítico}

- Continuar la lucha por la eliminación de todo tipo de segregación ocupacional basada en los sexos, abolir el desequilibrio salarial y establecer y fortalecer las medidas de protección que lleven a un equilibrio entre hombres y mujeres respecto a las responsabilidades reproductivas y familiares. Todo ello mediante el impulso de una política de trabajo decente [estos términos son también empleados por la Conferencia de la OIT, 96 Reunión, 2007, relativa a los principios y derechos fundamentales en el trabajo].

- Gestionar e incidir ante los gobiernos para que las mujeres sindicalistas participen en la discusión, adopción y mantenimiento de políticas macroeconómicas y estrategias de desarrollo que tengan en cuenta las necesidades y reivindicaciones de las mujeres trabajadoras, para eliminar las desigualdades de género y contribuir así a los esfuerzos por superar la pobreza.

- Presionar a los gobiernos y las instituciones a todos los niveles, para que adopten políticas públicas con asignación presupuestaria adecuada y la canalización de recursos sociales que contribuyan a lograr la igualdad de derechos, la igualdad de responsabilidades y la igualdad de oportunidades. 